\title{
Exploring the Experimental Teaching Mode of Economics and Management Based on Human-Machine Game under Big Data
}

\author{
Zhou Farong ${ }^{1, a}$, Zhang Yong Zhi ${ }^{2, b}$ \\ ${ }^{1}$ Chongqing University of Technology Economics Experimental Teaching Center Chongqing, China 400067 \\ ${ }^{2}$ Economic Management Experimental Teaching Center Chongqing, China 400067 \\ aE-mail: 853917491@qq.com \\ bE-mail: 1959475632@qq.com
}

Keywords: big data, management, man-machine game, experimental innovation zone

\begin{abstract}
Big data is closely related to economic management experiment teaching, and the economic experiment model of big data intelligent human-machine game is constructed to cultivate students' practical ability, innovative ability and improve teaching quality. Establish a smart big data teaching resource platform for human-machine games, build a basic functional area covering human-machine games, set up an open and shared big data mobile cloud platform, and create an economic management experimental teaching operation mechanism in line with the human-machine game under big data to reform Innovation is the core of the new experimental teaching model to enhance students' comprehensive practical ability.
\end{abstract}

\section{Introduction}

Applying big data, cloud computing and artificial intelligence technology to economic management experiment teaching, constructing an experimental teaching mode based on big data and human-machine game, it is imperative to improve the quality of economic management professional experimental teaching [1].

2. The motivation of the experimental teaching mode of the big data intelligent human-machine game

\subsection{Big Data Wisdom}

Big data (mega data), or huge amount of data, has the characteristics of huge data volume, various data types, low value density, and fast processing speed, which makes it have great potential value. The rapid development of big data technology has had a profound impact on various fields [2].

\subsection{Human-machine game and management experiment teaching}

The man-machine game is a game between humans and machines [2]. Introduce game theory and robotics into economic management experiment teaching to improve students' innovative practice ability.

\subsection{The existing experimental equipment under big data cannot meet the needs of human-machine game teaching}

The existing platform has the characteristics of huge data volume, various data types, low value density and fast processing speed. Big data processing can not meet the requirements [5], which is not conducive to students' practical ability training and students' innovation ability.

2.4 The mobile terminal enters the experimental system and needs an innovative experimental mode.

In the upcoming 5G era, big data technology makes it possible to analyze and mine the full 
amount of data, making the results of data analysis more general and versatile [3] how to meet the individualized experiment of students, fragmentation experiment requirements, piecemeal time training Experimental forms such as miniaturization of experimental projects require innovative experimental models.

\section{Constructing the Economics-based Experimental Teaching Mode of Big Data Intelligent Human-Machine Game}

\subsection{Construction objectives}

Relying on the platform of national experimental teaching demonstration center, with the core of cultivating and improving students' practical ability and innovation and entrepreneurship, we will establish the concept of whole-person education; innovate experimental teaching content and promote the reform of experimental teaching paradigm. In the experiment, the goal of knowledge transfer, theoretical innovation and student innovation practice ability is realized.

\subsection{Construction path}

Constructing an experimental experimental teaching model of big data intelligent human-machine game, developing a smart big data resource sharing cloud platform for management of human-computer games, building a human-machine game training functional area, an open mobile terminal platform area, and innovating Experimental teaching innovation experimental area including results incubation and promotion center. According to the time, students can choose their own methods and methods to conduct personalized independent experiments or training at their favorite moments and places.

\subsection{Construction Content}

1) Intelligent Big Data Cloud Platform for Managed Human-Machine Game.1 Integrate existing experimental courses and teaching software resource systems. Integrated experimental course (syllabus, experimental guide, software resources, $\mathrm{O} 2 \mathrm{O}$ network experiment) experimental teaching requirements. 2 data acquisition system: use web crawler technology to capture Internet data and provide basic data for data analysis. 3 data analysis system: create analysis tasks, edit tasks, task execution and task timing. 4 data visualization system: can be intuitive, vivid, interactive, personalized and customized visual chart. 5 intelligent big data cloud platform: market environment representation, law generator, search engine, and situation assessment are set in the platform, and the experimental functional area and the resource area are effectively combined.

2) Human-machine game experiment teaching function area.1 Game Design Development Zone: Develop and construct experimental zones suitable for functional areas and mobile platforms. 210 Tube Simulation Game Lab: Macroeconomic Operation Game Room, International Trade Simulation Room, Internet Finance Room, Quantitative Investment Lab, Statistical Application Game Room, Enterprise Management Decision Simulation Room, Human Resources Training Room, Marketing Game Room, Logistics System simulation room, entrepreneurial comprehensive simulation room. 3 Game Discussion and Analysis Area: Teacher Guidance Seminar, Game Analysis Room, Student Analysis Room. 4 Results release and summary area: used for student interaction salon, game defense, results release, summary and other activities.

3) Open shared big data mobile cloud platform.1 Mobile Experiment Course Resource Platform: Automatically integrate experimental course resources. 2 intelligent push system: from the experimental resource platform, according to the student's experimental project, experimental process and results, automatically push to meet the relevant content of the student's experiment. 3 Establish an Internet live broadcast system: complete the experiment through the live broadcast system. 4 Fragmented on-demand system: review and relearn the theoretical course. 5 Q\&A interaction system: The experimenters interact with each other in the experimental process to realize mutual problems and interaction between teachers and students. 6 Management system and automatic results generation system: curriculum resource management; team resource management; 
coordination arrangements, resource usage and statistical management of business development. 7 competitive game experimental cloud platform: to meet the student discipline competition and the competitive game in the course with the hierarchical structure of the platform [4].

4) Human-machine game results release and promotion center. The results release center and the results promotion center hatch and promote the innovation results such as research reports, analysis reports, databases, planning plans, design plans, and innovation (entrepreneurial) teams formed during the experimental process of human-machine games [5].

\section{Economic management experiment teaching operation mechanism of human-machine game under big data}

\subsection{Intelligent experimental teaching operation management system}

Through the establishment of the teaching resource platform and the human-machine game experimental teaching function area, the mobile terminal wisdom experiment teaching platform area, the human-machine game result release and promotion center and the experimental teaching management system are connected.

\subsection{Establishing intensive teacher resources}

Because of the huge amount of data, large data types, low value density, and fast processing speed of big data, it also includes business management, production technology, and public relations. Therefore, entrepreneurial instructors must also involve multiple fields; An advisory committee composed of experts from different fields to achieve intensive resource resources for the teaching staff. At the same time, it is also possible to build a high-quality experimental teaching team that understands the rules of experimental teaching through means of part-time employment, academic qualifications, domestic and international visits, and college observation training.

\subsection{Integration of resources in the training base}

Based on the economic management innovation and entrepreneurship training base, it will intensively train various training bases. Various training bases serve different role training tasks. For example, the computer training base can serve as the professional training for IT-based entrepreneurship projects, the mechanical training center serves as the mechanical professional training, and the biological training base serves as the biological and drug training. This will form an effective platform for intensive resources of the whole school with the economic management innovation and entrepreneurship training base as the center.

\subsection{Intensive social resources}

Social resources include human resources, technical resources, financial resources, and hardware resources. For colleges and universities, places and funds are relatively limited, so schools must gather resources as much as possible to reduce costs and improve efficiency. Actively establish contacts with venture capital companies to help students obtain more financial support [5]; the introduction of social resources can not only reduce school costs, but also share risks.

\section{Conclusion}

Based on big data, the human-computer game management professional innovation experimental area integrates new technologies such as Internet technology, artificial intelligence and human-machine game with teaching methods. It is an organic combination of game theory method and experimental teaching content, which enables the ability training to run through the course teaching. And the whole process of practice and experimental teaching. The establishment of the human-computer game management professional innovation experimental area based on big data will promote the reform and development of experimental teaching and enhance the comprehensive practical ability and innovation and entrepreneurial ability of economic management students. To lay a solid foundation for the cultivation of innovative talents and the improvement of talent quality. 


\section{References}

[1] Yao Haipeng et al. Introduction to Big Data and Artificial Intelligence [M]. Beijing: People's Posts and Telecommunications Press, 2017:9

[2] Yan Kuiming. Human-computer relationship in the era of big data [M]. Beijing: Beijing University of Aeronautics and Astronautics Press, 2016.7

[3] Li Jinchang: New thinking on big data and statistics [J] Statistical Research; 2014(1), 10-15

[4] Sun Chang. Construction and Practice of Economic Virtual Simulation Experiment Course System [J] Laboratory Research and Exploration 2018(1)157-160

[5] Wang Fang: Exploration of the reform of economics and experimental teaching under the background of big data [J] Laboratory Science; 2016(3), 72-75 